\title{
Effects of cigarette smoke on epithelial cells of the respiratory tract
}

\author{
Janice A Dye, Kenneth B Adler
}

\section{Department of Anatomy, Physiological Sciences, and Radiology, College of Veterinary Medicine, North Carolina State University, Raleigh, North Carolina 27606 USA \\ J A Dye \\ K B Adler}

Center for Environmental Medicine \& Lung Biology,

University of North

Carolina, Chapel Hill, North Carolina, USA J A Dye

Reprint requests to: Dr KB Adler.

Received 18 November 1993

Returned to author

16 February 1994

Revised version received 8 April 1994

Accepted for publication Accepted for pub
Chronic inhalation of cigarette smoke is associated with mucus hypersecretion, mucus pooling, pulmonary connective tissue damage, and chronic airflow obstruction.

Cigarette smoke has therefore been causally linked to the development of chronic obstructive pulmonary disease (either chronic bronchitis or emphysema), ${ }^{1}$ increased airway responsiveness, ${ }^{2}$ exacerbations of asthma, ${ }^{3}$ impaired pulmonary immune function, ${ }^{4}$ and increased pulmonary infections. ${ }^{5}$ Cigarette smoke has also been established as an important risk factor for lung, ${ }^{6}$ laryngeal, ${ }^{7}$ and nasal neoplasia. ${ }^{8}$ Pathogenetic mechanisms related to smoke-induced respiratory perturbations, however, are not fully understood.

One cell type in the lung that may play a major part in the pathogenesis of cigarette smoke-induced lesions is the airway epithelial cell. These cells line the lumen of the airways, and thus are in a unique position to interact directly with inhaled cigarette smoke. Most research involving cigarette smoke and airway epithelial cells has focused on the "target" cell responses of these cells in relation to their relatively simple roles in barrier and mucociliary clearance functions. Depending in part on the chronicity of exposure, certain functions may be altered - for example, ciliary beating, mucus secretion. It has recently become apparent, however, that airway epithelial cells may also act as "effector" cells, playing pivotal roles in regulation of airway reflexes, immunological and inflammatory responses, and maintenance of bronchodilation. As part of their overall response to chronic insult these cells are capable of producing and/or releasing a number of inflammatory mediators, or undergoing alterations in expression of cell adhesion molecules processes that may initiate or perpetuate airway inflammation. ${ }^{9}$ To date the influence of cigarette smoke on effector functions of epithelial cells has yet to be investigated in detail.

Much of the information presented herein is based on acute in vitro cigarette smoke exposures of epithelial cell cultures or airway explants, and on relatively acute human or laboratory animal exposures. Thus, non-neoplastic and non-emphysematous end points of respiratory disease have been emphasised. Nevertheless, early events in the response to cigarette smoke or its components may be critical, and certainly an understanding of these events may help to elucidate the pathogenetic mechanisms of many chronic respiratory diseases.

\section{Components of cigarette smoke}

Chemical analytical studies have identified over 3800 compounds in tobacco smoke. ${ }^{10}$ Mainstream cigarette smoke is composed of a complex mixture of gases and condensed tar particles. In experimental studies cigarette smoke is often separated into two phases by a glass fibre filter that retains nearly all particulate matter greater than $0.1 \mu \mathrm{m}$ in diameter. The retained particulate matter is commonly referred to as the "tar" phase, while the material passing through the filter is referred to as the "gas" phase. Known toxins and carcinogens have been identified in both the gaseous and particulate phases. ${ }^{11}$ Sidestream smoke (smoke emitted from the burning tip of the cigarette) is the major constituent of environmental tobacco smoke. The chemical composition and gas-toparticle associations of environmental tobacco smoke may be different from that of mainstream smoke, owing to prolonged time and cooling in the air. ${ }^{12}$ Sidestream cigarette smoke emissions contain carbon monoxide, ammonia, formaldehyde, benzene, nicotine, acrolein, various gases and particles, and an assortment of potentially genotoxic and/or carcinogenic organic compounds. ${ }^{13}$ Increased pulmonary particulate burden due to cigarette smoke may also play a part in respiratory disease..$^{14}$ Recent epidemiological findings have indicated adverse effects of particulate air pollutants at concentrations below currently permissible levels. ${ }^{15}$ Respirable suspended particles in indoor air in homes may increase from approximately $30 \mu \mathrm{g} /$ $\mathrm{m}^{3}$ to greater than $60 \mu \mathrm{g} / \mathrm{m}^{3}$ due to accumulation of environmental tobacco smoke. ${ }^{16}$

The reported effects of "cigarette smoke" may include that of mainstream smoke, variably aged environmental tobacco smoke/sidestream and exhaled smoke, gaseous phase components only, particulate phase components only, or individual chemical compounds such as acrolein, ${ }^{17}$ acetaldehyde, ${ }^{18}$ or formaldehyde. ${ }^{19}$ Some studies have used aqueous extracts of cigarette smoke obtained by bubbling the smoke through a buffer, with or without filtering to remove suspended particulates, ${ }^{20}$ while other researchers have focused on free radical production arising from chemical reactions within the cigarette smoke. ${ }^{21}$

Overall, owing to the variability in experimental methodologies (including the type of "cigarette smoke") used, interstudy comparisons may be difficult to interpret. It is well to keep this in mind when reading this review. 
Component cells of airway epithelium The airway epithelium is a mosaic of at least eight principal cell types, the exact composition of which may vary depending on the level of the airway and the species of interest. Ciliated epithelial cells and goblet cells form most of the luminal surface of the larger airways, and they are joined by tight junctions to form a relatively impermeable barrier to material from the luminal surface. ${ }^{22}$ The tight junctions are also important for polarised secretion and the selective permeability exhibited by airway epithelium. Other epithelial cell types (dependent on the species and airway level) include basal cells neuroendocrine cells, Clara cells, serous cells, small mucous granule cells, brush cells, and a variety of intermediate cell types. ${ }^{23}$ The nasal airways comprise a similar spectrum of cells together with several unique types required for olfaction (olfactory sensory and basal cells and the sustentacular cell).$^{23}$ Although the effects of cigarette smoke on nasal airways have been less extensively studied, significant exposure may result from nasal exhalation. Moreover, nasal epithelium is the first respiratory epithelial surface exposed to environmental tobacco smoke.

Airway epithelial surfaces are covered by a thin layer of mucus consisting of sol and gel fractions. In addition, mast cells or occasional lymphocytes are found within the airway epithelium or lumen, although more commonly in the submucosal layer. ${ }^{22}$ The epithelium also contains an abundance of nerve fibres whose receptors (irritant receptors, stretch receptors) run circumferentially around the luminal cells and respond to stimuli such as gases, smoke, or antigens. ${ }^{22}$ This review will focus on the epithelial cells that line the luminal surfaces of the conducting (non-gas exchange) airways. It should be kept in mind, however, that cigarette smoke-induced alterations in these cells may result in altered function of other airway epithelial components. For example, the cigarette smoke-induced increase in mucosal permeability may also allow increased access of the epithelial nerve receptors and mast cell populations to irritant or antigenic stimuli. ${ }^{22}$

\section{Histological changes in response to cigarette smoke}

Laboratory animals exposed to cigarette smoke develop histological changes in both the upper and lower airways (table 1). Hyperplasia and squamous metaplasia of the respiratory epithelium of the dorsal nasal turbinates was observed in rats following exposure to sidestream cigar-

Table 1 Histological changes of the respiratory tract associated with exposure to cigarette smoke

Airway epithelial hyperplasia

Nasal respiratory epithelial hyperplasia

Airway mucous cell hyperplasia

Airway submucosal gland hypertrophy

Intraluminal, mucosal, and parenchymal inflammation

Emphysema

Hyperplasia of pulmonary neuroendocrine cells

Reduction of pulmonary lymphoid cells (for example, BALT)

Squamous metaplasia of airway and nasal epithelium

Preneoplastic and neoplastic lesions ette smoke for 90 days. ${ }^{24}$ Mice inhaling cigarette smoke developed basal cell hyperplasia and squamous metaplasia of the nasal cavity, as well as hypertrophy of Clara cells. ${ }^{25}$ In a cigarette smoke-induced model of "bronchitis" exposure of Sprague-Dawley rats to smoke (25 cigarettes/ day for 14 days) increased epithelial thickness at three of the four airway levels assessed due to a $100-400 \%$ increase in the number of secretory cells. ${ }^{26}$ Initial changes included basal cell proliferation accompanied by mucous metaplasia of surface epithelial serous cells, and proliferation of the newly formed mucous cells. The acidic glycoprotein-containing secretory cells were dramatically increased in number, while the neutral glycoprotein-containing secretory cells were decreased. Histological changes in airways of patients with chronic bronchitis also included mucous cell hyperplasia and hypertrophy of submucosal glands with a shift to acidic, sialidase resistant, intracellular glycoproteins.

When non-steroidal anti-inflammatory drugs or corticosteroids were given concurrently with smoke exposure in a rat model of bronchitis, smoke-induced mucous cell hyperplasia was variably inhibited, depending on the drug and level of the airways examined. ${ }^{27}$ Additional studies found that after cigarette smoke exposure in the rats the time required for secretory cell hyperplasia to resolve was shorter in larger than smaller airways - for example, trachea nine days; distal bronchioles up to 84 days. ${ }^{28}$ Treatment with non-steroidal anti-inflammatory drugs during the recovery period hastened the return to normal epithelial architecture in the smaller airways (to 4-9 days) but had no effect on tracheal recovery. ${ }^{29}$ Treatment of rats with $1 \% N$-acetylcysteine during the recovery period also reduced the time for secretory cell numbers to return to normal. ${ }^{30}$ Furthermore, concurrent administration of $N$-acetylcysteine with cigarette smoke exposure inhibited the initial increase in the number of acidic glycoprotein-containing secretory cells, but had little effect on numbers of cells containing neutral glycoproteins. ${ }^{26}$

Balansky et $a l^{31}$ exposed Sprague-Dawley rats to cigarette smoke once daily for 40 days and observed dramatic histological changes in terminal airways, including severe neutrophilic infiltration of the mucosa, hyperplastic and metaplastic lesions, and micropapillomatous foci. Concurrent administration of $\mathrm{N}$-acetylcysteine effectively prevented these changes. Studies in humans have also shown significantly increased numbers of total inflammatory cells and polymorphonuclear leucocytes in walls of membranous bronchioles in smokers. This response does not subside following smoking cessation as both current and ex-smokers had similar numbers and types of inflammatory cells in their airway walls. ${ }^{32}$

Inhaled cigarette smoke also induces preneoplastic changes in rat tracheal epithelial cells, lesions influenced by dietary deficiencies. In vitamin $\mathrm{A}$ (retinoic acid) deficient rats cigarette smoke caused epidermoid metaplasia characterised by stratified, keratinised, and squamous epithelial changes, ${ }^{33}$ and focal areas of 
squamous metaplasia including extensive squamous metaplasia of the larynx..$^{34}$ Conversely, when neonatal rat tracheas in organ culture were treated simultaneously with an experimental retinoid compound (Ro 15-0778), lesions associated with cigarette smoke condensate (hyperplasia, metaplasia, loss of secretory activity, and ciliary function) were prevented. ${ }^{35}$ To our knowledge similar studies have not been performed in humans, although several investigators are evaluating a potential use for retinoids in preventing or reversing metaplastic changes in airway epithelium at the molecular level. Much of this work has been done with in vitro models.

\section{Effects of cigarette smoke on epithelial barrier function}

In airway epithelia tight cell-cell and cellmatrix contact allows for maintenance of a relatively impermeable (or selectively permeable) barrier between the airway lumen and underlying submucosal and vascular components of the respiratory system. Owing in part to this barrier, specific transport mechanisms of airway epithelia can regulate chloride secretion or sodium absorption and precisely maintain the amount and composition of respiratory tract lining fluid. Alterations in this fluid occur when normal airway epithelial function is disrupted by disease states such as cystic fibrosis, or exogenously derived perturbation such as cigarette smoking. Although not specific for cigarette smoking, processes that alter integrity of the airway epithelium (especially that of the alveolar spaces) are associated with an increased rate of ${ }^{99 \mathrm{~m}} \mathrm{Tc}$-DTPA clearance. Using ${ }^{99 \mathrm{~m}} \mathrm{Tc}$-DTPA thoracic scintigraphy has confirmed that lungs of smokers are more permeable than those of non-smokers. ${ }^{36}$ Increased epithelial permeability occurs at an early stage in asymptomatic or neophyte smokers. ${ }^{37}$ Rapid clearance is promoted by increased lung volumes and decreased surfactant secretion; however, the exact mechanism(s) for increased ${ }^{99 \mathrm{~m}} \mathrm{Tc}-\mathrm{DTPA}$ clearance in these states is unknown. ${ }^{38}$

Cigarette smoke-induced changes in ${ }^{99 \mathrm{~m}} \mathrm{Tc}$ DTPA clearance could reflect alterations in permeability of pulmonary vasculature ${ }^{39}$ alveolar permeability, and/or altered integrity of the conducting airways. Cigarette smoke increases endothelial permeability by its effects on cytoskeletal elements as shown in porcine pulmonary artery preparations, ${ }^{40}$ tachykinin release in rat nasal passageways, ${ }^{40}$ and cation influx in rat airway vasculature ${ }^{41}$ Following cigarette smoke exposure in guinea pigs changes in alveolar permeability were associated with type I cell injury.$^{42}$ In rabbits acute cigarette smoke exposure was associated with increased ${ }^{99 \mathrm{~m}} \mathrm{Tc}$-DPTA clearance, histological focal alveolar oedema and haemorrhage, but no ultrastructural changes in the alveolar capillary membrane. ${ }^{43}$ Increased ${ }^{99 \mathrm{~m}} \mathrm{Tc}$-DPTA clearance occurred in rats exposed to cigarette smoke, but light microscopically detectable abnormalities were not seen in the lung parenchyma. ${ }^{44}$

Increased permeability of the airway epithelium to large molecular weight molecules (for example, dextran ${ }^{45}$ ) has been demonstrated in guinea pigs following inhalation of cigarette smoke, and appeared to be linked to damage to epithelial tight junctions. ${ }^{46}$ Bronchial epithelial cells exhibited increased detachment following application of proteases to their apical surface when cultures were first exposed to cigarette smoke extract (also on their apical surface). ${ }^{47}$ These results suggest that an intact airway epithelium is an important barrier against proteases released from intraluminal inflammatory cells.

Exposure of primary hamster tracheal epithelial cells to non-toxic concentrations of cigarette smoke extract inhibited intercellular communication across gap junctions. ${ }^{48}$ In primary chick embryo hepatocytes cigarette smoke condensate induced a greater than $60 \%$ reduction in gap junction numbers. ${ }^{49}$ Furthermore, the number of gap junctions and the rate of gap junction communication was inhibited by cigarette smoke condensate from tobacco-burning, but not tobacco-heated, cigarettes in cultured rat hepatic epithelial cells and human fibroblasts. ${ }^{50}$

Taken together, these studies indicate that cigarette smoke and/or many of its components can have a number of deleterious effects on intercellular communication and epithelial permeability. These alterations can play a part in the development of chronic respiratory diseases.

\section{Alterations in airway secretions and ciliary clearance apparatus}

It is beyond the scope of this report to review the structure and synthesis of mucins and structure and function of cilia. Readers are referred to several excellent review articles in this area. ${ }^{51}$ Briefly, mucociliary clearance is dependent on the coordinated activities of (a) normal ciliary structure and function, (b) appropriate quantities and physicochemical properties of mucus, and (c) appropriate quantity (depth) of periciliary lining fluid. Alteration or dysfunction of any one of these components may result in reduced efficiency of the entire mucociliary clearance escalator. ${ }^{52}$

Cigarette smoke has profound effects on mucociliary function but the underlying mechanisms have not been elucidated. Studies have been hampered by: (a) complex interrelationships between various components of the mucociliary apparatus; (b) the complexity of the cigarette smoke mixture; (c) the fact that studies on the time course of particle clearance depend, not only on mucociliary velocity, but on initial particle distribution and deposition patterns; ${ }^{53}$ and (d) the fact that acute effects of cigarette smoke in naively exposed subjects do not necessarily reflect those found in chronically exposed subjects. ${ }^{53}$ Effects of cigarette smoke on mucociliary function have been reviewed previously. ${ }^{52}$

Environmental cigarette smoke exposure has been implicated increasingly in the development of upper respiratory tract infections and otitis media, especially in children. ${ }^{54}$ Cigarette smoke and other indoor air pollutants have been shown to alter upper airway mucociliary func- 
tion. Nasal mucociliary clearance in asymptomatic smokers was longer than in lifelong nonsmokers, although no differences were detected in the mean nasal ciliary beat frequency..$^{55}$ Conversely, acute exposure to cigarette smoke in the rabbit was associated with increased mucociliary activity of the maxillary sinuses. These effects, however, were mediated reflexly via NK1 receptor stimulation by tachykinins released secondarily to irritant effects of cigarette smoke on sensory afferent nerves in the upper airways. ${ }^{56}$

Tracheal mucus from asymptomatic smokers is increased in both volume and water content, with a lower total solid content than mucus from non-smokers. This mucus caused increased mucociliary "clearability" in frog palate transport assays. ${ }^{57}$ Significant elevations of a macrophage-derived mucus secretagogue (MMS-68) have been detected in the bronchoalveolar lavage fluid of cigarette smokers. ${ }^{58}$ Tracheal potential differences, a measurement of transepithelial electrical potential difference used to assess ion permeability and ion transport across respiratory epithelia, were reduced in chronic cigarette smokers. ${ }^{59}$

Under similar airway deposition patterns inner lung zone clearance of particles (as assessed by gamma camera imaging) was significantly slower in asymptomatic smokers than in age matched non-smoking controls. ${ }^{60}$ Alveolar deposition after 24 hours, however, was reduced, suggesting that smokers have a greater proportion of small conducting airways capable of mucociliary clearance. ${ }^{61}$ These findings may be related to smoking-induced changes in bronchiolar secretory cells where secretion of crosslinked mucus glycoproteins is enhanced, increasing the efficiency of mucus-cilia coupling. Non-smokers have poorer mucociliary defence capabilities in their more distal peripheral airways, which would not be necessary unless chronic insults arose. In these asymptomatic subjects cigarette smoke-associated alterations in mucus may be beneficial. Inhalation of smoke from a single cigarette acutely (and reversibly) decreased the electrical potential difference across canine tracheal epithelium. ${ }^{62}$ Both in vivo and in vitro acute exposure of cigarette smoke in the dog inhibited active ion transport (chloride secretion) by tracheal epithelium. ${ }^{62}$ Chronic smoke exposure in the dog (10 cigarettes/day for 10 months) caused persistently increased tracheal mucus flux. ${ }^{63}$

In vivo and in situ animal studies have been used to dissect the reflex secretory responses induced by cigarette smoke. Reflexes initiated by nervous receptors in the airways normally augment mucus secretion in response to airway insult. Absorbed nicotine, however, bypasses its usual reflex circuits by directly stimulating ganglion cells. ${ }^{64}$ In guinea pigs acute inhalation of low doses of cigarette smoke stimulated airway goblet cell secretion by activating cholinergic nerves (via parasympathetic ganglion stimulation) whereas exposure to high doses of the vapour phase of cigarette smoke stimulated capsaicin-sensitive sensory nerve endings ${ }^{65}$ In rats both control and previously exposed "bronchitic" animals showed exhibited tran- sient increases in fucose (a mucus marker) secretion when cigarette smoke was blown through their laryngotracheal segments in situ. ${ }^{66}$ In the cat in situ studies have indicated the complexity of reflex responses involved; cigarette smoke passed directly into the feline trachea segment stimulated mucin secretion, while smoke passed directly into the lower airways stimulated secretion in the lung segment. If cigarette smoke was first passed through the larynx, however, no augmentation occurred. It seems necessary for nicotine to be absorbed either directly into the tracheal segment or into the blood (via the alveolar spaces) for the autonomic ganglia innervating the airway submucosal glands to be stimulated. This reflex pathway predominates over that of airway irritant reflexes. ${ }^{67}$

Nicotine was a powerful mucus secretagogue when applied to ferret tracheal segments in vitro. ${ }^{68}$ Exposure of organ cultures of rat trachea to cigarette smoke condensate induced loss of secretory activity and ciliary function,,$^{35}$ and exposure of rat tracheal explants to varying amounts of cigarette smoke for 10 minutes induced dose-related blebbing of the apical membrane and loss of cilia. ${ }^{69}$ The cigarette smoke component acrolein reduced ciliary beat frequency in cultured bovine bronchial epithelial cells, ${ }^{70}$ while acetaldehyde - another major component of tobacco smoke - impaired ciliary function and beat frequency by inhibiting ciliary dynein ATPase activity and binding to ciliary proteins critical in the functioning of dynein and tubulin. ${ }^{71}$

Thus, cigarette smoke and/or many of its components can have direct effects on the secretory and transport functions of airway epithelial cells. Obviously such alterations can play an important part in the pathogenesis of chronic airway disease - for example, decreased mucociliary clearance can result in airway obstruction and increased susceptibility to microbial infection.

\section{Influences of cigarette smoke on airway epithelial regulatory functions AIRWAY NEUROPEPTIDE REFLEX RESPONSES AND BRONCHOCONSTRICTION}

Airway reflex responses to irritants such as cigarette smoke are important in mediating changes in mucus secretion and these pathways often involve release of tachykinins, a family of neuropeptides including substance $P$, neurokinin A, and neurokinin B. When released from sensory nerve endings in the airways tachykinins act on various receptors eliciting a typical pattern of response. These collective effects often referred to as "neurogenic inflammation" - include mucus hypersecretion, smooth muscle contraction, increased airway mucosal plasma extravasation (associated with increased vascular permeability), increased neutrophil adhesion, and cough. ${ }^{72}$ Tachykinins are normally rapidly hydrolysed by the membranebound metalloenzyme, neutral endopeptidase (NEP), which is widely distributed in the airways. Excessive release of tachykinins, however, decreases the capacity of NEP enzymatic degradation, or a combination of these effects 
may result in exaggerated neurogenic responses.

Cigarette smoke exposure stimulated primary afferent sensory nerves in rats, eliciting tachykinin release and resultant mucosal oedema of tracheal tissue. ${ }^{73}$ Chemical irritants in the vapour phase of cigarette smoke are primary elicitors of the permeability response. ${ }^{74}$ Inhalation of cigarette smoke in guinea pigs also augments airways responsiveness to inhaled substance $P$ and capsaicin, ${ }^{74}$ effects associated with decreased airway NEP activity. ${ }^{75}$ Supernatants from bovine bronchial epithelial cells exposed to tachykinins exhibited increased neutrophil chemotactic activity, ${ }^{76}$ and direct pretreatment of bovine bronchial epithelial cells with substance $P$ significantly increased adherence of cocultured neutrophils. ${ }^{77}$

Pulmonary neuroendocrine cells - for example, neuroepithelial bodies and small granule cells - are a poorly understood group of epithelial cells in the airways, and cigarette smoking has been associated with this hyperplasia and variable increases in respiratory tract concentrations of the bombesin-related peptides. ${ }^{78}$ Bombesin-related peptides are a family of neuropeptides similar to amphibian bombesin. They are present in several human body systems including the respiratory tract where they have a role(s) in immunological lung functions. ${ }^{79}$ They exert chemoattractant activity for monocytes, mitogenic activity for bronchial epithelial cells, and bronchoconstrictive activity. These peptides are involved in cigarette smoke-associated lung inflammation, fibrosis, and/or airway obstruction, ${ }^{79}$ and function as essential autocrine factors for many small cell lung cancers. Since cigarette smoke inactivates NEP, and NEP normally hydrolyses bombesinrelated peptides, it has been proposed that decreased airway NEP activity may also be causally related to the development of these carcinomas. ${ }^{80}$

Nitric oxide exhibits potent relaxing activity in both canine and guinea pig airways. ${ }^{81}$ Unstimulated bovine bronchial epithelial cells in culture are capable of converting L-arginine to L-citrulline, one of the biosynthetic pathways of nitric oxide. ${ }^{82}$ Moreover, exposure of the epithelial cells to cigarette smoke extract prevented this conversion, as did treatment of the cells with competitive inhibitors of nitric oxide synthase. ${ }^{82}$ Competitive inhibitors of nitric oxide synthase also decrease ciliary beat frequency in cultured bronchial epithelial cells, ${ }^{83}$ and the free radical reactant product of nitric oxide and low molecular weight thiols can form $S$-nitrosothiol adducts which have potent relaxation effects on airway smooth muscle. ${ }^{84}$

Finally, another potential cause of smokeinduced airway obstruction could be the development of airway inflammation and associated increases in release of cytokines. For example, guinea pig tracheas cultured with inflammatory cytokines such as IL-8 and TNF $\alpha$ demonstrated increased synthesis of endothelin-1, a potent bronchoconstrictor. ${ }^{85}$

AIRWAY INFLAMMATION

Perturbations of the airway epithelial cell bar- rier induced by cigarette smoke may lead to adverse changes resulting in airway inflammation (table 2). Specific mechanisms involved in this inflammation include: (a) increased synthesis and/or release of inflammatory mediators (for example, arachidonic acid metabolites, chemotactic agents) or, alternatively, decreased synthesis of protective mediators (for example, chemotactic factor inactivators); (b) synthesis of proinflammatory cytokines; (c) modulation of cell adhesion molecules; and (d) modulation of immunoregulatory processes.

Cigarette smoke induces an acute inflammatory reaction in the airways and lung parenchyma. Peripheral leucocytosis ${ }^{86}$ and increases in bronchoalveolar lavage neutrophil and total inflammatory cell counts have also been demonstrated in cigarette smokers. ${ }^{87}$ In one study both current and ex-smokers had increased total inflammatory cells and neutrophils in the walls of their membranous bronchioles compared with non-smokers, ${ }^{32}$ and they also had similar numbers and types of airway inflammatory cells present regardless of concurrent emphysematous changes..$^{3288}$

Airway epithelial cells are an important source of inflammatory mediators ${ }^{9}$ since responses to various stimuli may involve epithelial release of chemotactic activity for leucocytes. ${ }^{89}$ Cigarette smoke has proved to be a "reliable" stimulus for inducing release of such chemotactic activity, although the specific mediators released vary among species in both in vivo and in vitro studies. Exposure of young non-smoking humans to environmental tobacco smoke for three hours promoted systemic priming of neutrophils and increased circulating neutrophil counts, neutrophil chemotaxis, and neutrophil release of oxidants upon stimulation. ${ }^{90}$ Similarly, human bronchial epithelial cell cultures exposed to smoke extract release significantly greater neutrophil chemotactic activity than controls. ${ }^{82}$ Nitric oxide appeared to play a part in this response as pretreatment of the cultures with a nitric oxide synthase inhibitor (L-NMMA) abrogated this increase, while addition of L-NMMA to supernatants failed to inhibit neutrophil chemotactic activity. ${ }^{82}$

At concentrations comparable to levels observed in the plasma of smokers nicotine appeared to enhance the neutrophilic response to other chemotactic peptides. ${ }^{91}$ At higher concentrations, however, nicotine inhibited the neutrophil chemotactic response and sponta-

Table 2 Potential mechanisms of epithelial cells serving as effector cells

Neutral endopeptidase enzymatic degradation of tachykinins Production of bombesin-related peptides

Production of nitric oxide

Production of endothelin-1

Major histocompatibility complex class II antigen expression

Production of arachidonic acid metabolites (for example, prostaglandins, thromboxanes, leukotrienes,

prostaglandins, thromboxanes,
hydroxyeicosotetraenoic acids)

hydroxyeicosotetraenoic acids)
Production of chemotactic agents

Production of chemotactic agents
Production of chemotactic factor inactivators

Cytokine production (for example, GM-CSF, G-CSF, IL-6, IL-8)

Cell adhesion molecule changes (for example, ICAM-1)

Production of fibronectin and other extracellular matrix molecules 
neous migration..$^{92}$ Nicotine pretreatment of mice appeared to enhance neutrophil influx towards the "source of inflammation" when the chemotaxin, zymosan-activated serum, was injected into the pleural space..$^{92}$

Smoke-induced recruitment of neutrophils was complement-dependent in mice: C5-sufficient mice, but not $\mathrm{C} 5$-depleted mice, exposed to cigarette smoke had increased neutrophil chemotactic activity in their bronchoalveolar lavage fluids.$^{93}$ Others suggest that the mechanism of neutrophil influx into the lungs relates to smoke-induced loss of functional activity of chemotactic factor inactivator (CFI). CFI normally inhibits C5a-directed neutrophil chemotaxis by binding to GcGlobulin, an essential cochemotaxin of $\mathrm{C} 5 \mathrm{a} .{ }^{94}$ While specific smokeinduced effects on other airways or alveoler protease inhibitors remain largely unknown, cigarette smoke inactivation of $\alpha$-protease inhibitor is a contributing factor in the development of smoking-related emphysema..$^{95}$

Airway epithelial cells contain both linoleic acid and arachidonic acid, which are available for metabolism and release via oxidative pathways and are capable of metabolising arachidonic acid to prostaglandins, thromboxanes, leukotrienes, and hydroxyeicosotetraenoic acids (HETEs), although the exact profile of eicosanoids is dependent on the species of origin and the nature of the stimulus - for example, ozone, nitrogen dioxide. ${ }^{9697}$ Since these eicosanoids are associated with effects ranging from enhanced mucus secretion to smooth muscle contraction and inflammatory cell chemotaxis their release following exposure to cigarette smoke has also been evaluated. In humans cigarette smoking causes increased urinary excretion of the 2,3dinor metabolites of thromboxane $\mathrm{A}_{2}$, but not prostacyclin (PGI), ${ }^{98}$ and reduces salivary concentrations of $\mathrm{PGE}_{2}, \mathrm{PGF}_{2 x}$, leukotrienes, and 12-HETE. ${ }^{99}$ Bronchoalveolar lavage fluid obtained from Wistar rats exposed to cigarette smoke contained increased concentrations of 15-HETE but not thromboxane $\mathrm{B}_{2} .{ }^{100}$ Conversely, bronchoalveolar lavage fluid from guinea pigs exposed to acrolein (a low molecular weight aldehyde found in cigarette smoke) had increased concentrations of both $\mathrm{PGF}_{2 x}$ and thromboxane $\mathrm{B}_{2}{ }^{101}$ In vitro exposure of bovine tracheal epithelial cells to non-cytotoxic concentrations of acrolein caused increased release of $\mathrm{PGE}_{2}, \mathrm{PGF}_{2 x}, 6$-keto-PGF $1 x, 12-\mathrm{HETE}$, and 15-HETE. Exposure of isolated rat tracheal segments to cigarette smoke extract elicited a biphasic effect on muscarinic-stimulated eicosanoid synthesis: low concentrations potentiated production while higher concentrations inhibited this response. ${ }^{102}$ Exposure of canine mast cells to cigarette smoke solution inhibited $\mathrm{PGD}_{2}$ production but induced increased release of the preformed mediators, histamine and tryptase. ${ }^{103}$

Research over the last decade has expanded our knowledge of cytokines and their networks and their role in inflammatory responses of the respiratory tract. Airway epithelial cells themselves are now known to be capable of synthesising, releasing, and/or upregulating production of these locally acting mediators. Analysis of conditioned medium from human bronchial epithelial cells in primary culture demonstrated the presence of GM-CSF, G-CSF, and IL-8. ${ }^{104}$ The presence of GM-CSF and G-CSF in the conditioned media caused increased in vitro survival of cultured peripheral blood neutrophils. ${ }^{104}$ IL-8 is the major cytokine of the human nasal epithelium, ${ }^{105}$ although conditioned media from human nasal epithelial cell cultures also contained GM-CSF, G-CSF, and IL- $6 .{ }^{106}$ There are too few data available on the influence of cigarette smoke on cytokine production by airway epithelial cells, but exposure of human alveolar epithelial cells to a phenol-rich glycoprotein present in cigarette smoke condensate was associated with increased synthesis of IL-1 and IL-6. Exposure also elevated steady state levels of mRNAs for IL-1, IL-6, and platelet derived growth factor (PDGF-A and PDGF-B) as detected by in situ nucleic acid hybridisation. ${ }^{107}$ As assessed by bioassays, cigarette exposure of cultured human and guinea pig alveolar macrophages decreased IL7 and TNF activity. ${ }^{108}$ Additionally, lipopolysaccharide-stimulated alveolar macrophages from smokers caused less IL-1 and IL-6 production than alveolar macrophages from non-smokers. ${ }^{109}$ This may be important for the increased susceptibility of smoking patients to respiratory infections, and to the decreased incidence of immune-mediated pulmonary diseases such as sarcoidosis in smokers. ${ }^{110}$

Human bronchial epithelial cells have recently been shown to express the $\alpha_{2-6}$ integrins, molecules which interact with many extracellular matrix components. Cultured human respiratory cells also express intercellular adhesion molecule 1 (ICAM-1) on their surfaces. Adherence of neutrophils to airway epithelial cells via ICAM-1 may be an important factor in inflammatory airway diseases. ${ }^{111}$ The processes by which neutrophils migrate to sites of airway inflammation are complex and beyond the scope of this report. Briefly, however, as reviewed recently, ${ }^{112}$ initial steps of neutrophil recruitment involve a process known as "rolling" whereby neutrophils begin to decelerate and attach to the endothelial surface of postcapillary venules at or near sites of tissue injury or inflammation. Adhesion molecules of the selectin family (P-, E-, and L-selectin) are essential components in this process. Neutrophils subsequently arrest and spread over the endothelial cell surface via interactions between their $\beta_{2}$-integrins $(\mathrm{CD} 11 \mathrm{a} / 18$ and $\mathrm{CD} 11 \mathrm{~b} / 18$ ) and endothelial cell ICAM-1. Once firmly attached, leucocytes migrate through vessel walls, extracellular matrix components, and between normally adherent epithelial cells following chemotactic and/or haptotactic gradients. Migration requires careful regulation of proteolytic enzyme secretion and transformation of the cell into a deformable, motile state. Once near or at the site of airway injury or inflammation, leucocyte retention involves critical concentrations of specific cytokine(s) for example, GM-CSF - and continued interaction with epithelial cell adhesion molecules. Interestingly enough, proinflammatory cytokines - for example, IL-1, TNF $\alpha$ - increase cell 
surface expression of ICAM-1 and neutrophil adhesion to tracheal epithelial cells in vitro. ${ }^{111}$ Selective induction of human tracheal ICAM-1 expression in human tracheal epithelial cells has also been shown in response to interferon $\gamma$ treatment.

Cigarette smoke elicits a number of neutrophil migratory and cell adhesion changes. Neutrophil transit time through the human pulmonary vasculature is prolonged by inhalation of cigarette smoke. ${ }^{112}$ Studies in rabbits have shown that smoking-induced neutrophil retention in pulmonary vasculature occurs without corresponding changes in pulmonary haemodynamics. ${ }^{113}$ In hamsters acute exposure to mainstream smoke for five minutes provoked neutrophil rolling and subsequent adhesion to the endothelium of both postcapillary venules and arterioles. Adhesion steps were mediated via 5-lipoxygenase metabolites of arachidonic acid (leukotrienes). ${ }^{114}$ In vitro exposure of neutrophils to both the whole particulate and vapour phase of cigarette smoke reduced the deformability (hence migratory capability) of neutrophils via effects on the actin component of their cytoskeleton. ${ }^{115}$ Also, plasma myeloperoxidase concentrations are elevated immediately after exposure to cigarette smoke which suggests that cigarette-induced lung damage is related to activation of leucocytes still within the pulmonary capillary bed. ${ }^{113}$ Further evidence is provided by intravascular neutrophils in certain lung regions of rabbits exposed to smoke which showed increased expression of CD11/CD18 coincident with decreased L-selectin expression. ${ }^{116}$ After subacute (two week) exposure rats did not show altered endothelial neutrophil adhesion compared with shamexposed animals; however, after treatment with capsaicin they had more vascular adherent neutrophils, suggesting that cigarette smoke potentiates neutrophil adhesion in association with neurogenic airway inflammation. ${ }^{117}$ Exposure of monolayers of bovine bronchial epithelial cells to cigarette smoke extract significantly increased adherence of both cocultured neutrophils and mononuclear cells. ${ }^{118}$ Peripheral blood neutrophils exposed to cigarette smoke in vitro and then cocultured with alveolar epithelial cells demonstrated decreased adherence which did not increase after stimulation with f-Met-Leu-Phe. ${ }^{119}$

As mentioned previously, cigarette smoking is associated with a decrease in certain immune mediated pulmonary disease ${ }^{110}$ while smoking and/or exposure to environmental tobacco smoke has been associated with increased respiratory infections including sinusitis, otitis media, bronchitis, and pneumonia, ${ }^{5}$ conditions presumably related to alterations in immune function. ${ }^{120}$ Immunological effects induced by cigarette smoke include reduction of bronchus associated lymphoid tissue (BALT), decreased immunoglobulin concentrations due to suppression of B cell antibody production (except for IgE, which is increased), decreased helper $T$ cell numbers, decreased natural killer cell activity, and increased circulating soluble IL-2 receptors. ${ }^{120121}$ Infections asociated with cigarette smoke may be related to effects such as decreased mucociliary clearance of inhaled infectious agents. Other smoking-related immunological effects on airway epithelial function could involve alterations in the expression of major histocompatibility complex class II antigen (MHC class II) or alterations in the function of airway dendritic cells. Expression of MHC class II antigens was increased in bovine bronchial epithelial cells exposed to supernatants from activated lymphocytes. ${ }^{122}$ Antigen presenting functions of pulmonary dendritic cells (which typically express ICAM-1) are downregulated via interactions with resident alveolar macrophages.

Repair of injured areas of airway epithelium (resulting from either direct cigarette smokeinduced injury or as a consequence of airway inflammatory processes) may be impaired by ongoing cigarette smoke exposure. Cigarette smoke degrades hyaluronic acid, ${ }^{123}$ decreases fibronectin release from cultured bovine bronchial epithelial cells, ${ }^{124}$ and delays migration of bronchial epithelial cells to fibronectin. ${ }^{125}$

The airway epithelial cell therefore has the potential to act as an inflammatory cell, responding to smoke/and or many of its components by releasing a number of humoral and inflammatory mediators that may enhance the inflammatory reaction in the airways and contribute to the pathogenesis of chronic disease. The role of airway epithelial cells as potential effector cells in the response to smoke or many other insulting or injurious agents is a research area that has received much recent attention, and it is possible that these cells can produce a number of other as yet unidentified compounds that can contribute to airway inflammation.

\section{Cigarette smoke combined with other pulmonary insults}

Synergistic effects of cigarette smoke with other respiratory insults have been reported - for example, a synergistic effect of asbestos exposure and cigarette smoke in bronchogenic carcinoma. ${ }^{126} \mathrm{~A}$ mechanism of this synergy suggests that both deleterious agents provoke generation of reactive oxygen species in the airways. ${ }^{127}$ In guinea pigs exposure to cigarette smoke combined with intratracheal instillation of amosite asbestos fibres resulted in increased penetration of the asbestos fibres into the airway walls. ${ }^{128}$ Cigarette smoke exposure also impairs clearance of amosite asbestos fibres (particularly the shorter fibres) from both alveolar macrophages (30-fold increase in fibre number) and pulmonary tissue (eightfold increase). ${ }^{129}$ Excised rat tracheal segments exposed to cigarette smoke followed by amosite asbestos have increased epithelial uptake of the fibres, and uptake was still enhanced wher. smoke exposure preceded asbestos treatment by up to 48 hours. ${ }^{130}$ Again, reactive oxygen species played a part in smokemediated fibre transport into the tracheal epithelium. ${ }^{131}$ Cigarette smoke exposure of tracheal epithelial explants also directly enhanced uptake of inert dust - that is, non-fibrous titanium dioxide, talc, and fibrous silicon carbide - while treatment with scavengers of reactive oxygen species only blocked uptake of some of these particles. ${ }^{132}$ Finally, exposure to cigar- 
ette smoke has also been associated with potentiation of pulmonary injury following instillation of bleomycin, ${ }^{133}$ irradiation-induced pneumonitis, ${ }^{134}$ and ozone inhalation. ${ }^{135}$

\section{Conclusions}

Cigarette smoke and many of its individual components, both gaseous and particulate, can generate various lesions in epithelial cells of the airways. Interactions between these stimuli and airway epithelial cells are just beginning to be elucidated. Although studies of cigarette smoke-induced effects on individual cells of the airway epithelium are exceedingly useful for eliciting underlying mechanisms of respiratory injury and disease, the overall respiratory system response depends ultimately upon the integrated action of all effector cell populations with their corresponding target cells. To fully understand how defence mechanisms within the respiratory system attempt to intervene against cigarette smoke while attempting to repair previous smoke-induced damage, these interactions of airway epithelial cells with other host defence/repair mechanisms must be more completely understood.

1 Fletcher CM, Peto R. The natural history of chronic airflow obstruction. BMf 1977;1:1645-8.

2 Gerrard JW, Cockcroft DW, Mink JT, Cotton DJ, Poonawala R, Dosman JA. Increased nonspecific bronchial reactivity in cigarette smokers with normal lung function Am Rev Respir Dis 1980;122:577-81.

3 Chilmonczyk BA, Salmun LM, Megathlin KN, Neveux LM, Palomati GE, Knight GJ, et al. Associations between exposure to environmental tobacco smoke and exacer-
bations of asthma in children. $N$ Engl $f$ Med 1993;328:1665-9.

4 Hoidal JR, Niewoehner DE. Lung phagocyte recruitment and metabolic alterations induced by cigarette smoking in humans and in hamsters. Am Rev Respir Dis humans and in

5 Marcy TW, Merrill WW. Cigarette smoking and respiratory tract infection. Clin Chest Med 1987;8:381-91

6 International Agency on the Research of Cancer. IARC Monograph on the Evaluation of the Carcinogenic Risks of
Chemicals to Humans: Smoking. Lyon, France: IARC, 1986;38:199-243

7 Muscat JE, Wynder EL. Tobacco, alcohol, asbestos, and occupational risk factors for laryngeal cancer. Cancer 1992;69:2244-51.

8 Brinton LA, Blot WJ, Becker JA, Winn DM, Browder JP, Farmer JC Jr, et al. A case-control study of cancers of the nasal cavity and paranasal sinuses. Am $\mathcal{f}$ Epidemio 1984;119:896-906.

9 Cohn LA, Adler KB. Interactions between airway epithelium and mediators of inflammation. Exp Lung Res 1992;18:299-322.

10 Brunnemann KD, Hoffmann D. Analytical studies on tobacco-specific N-nitrosamines in tobacco and tobacco smoke. Crit Rev Toxicol 1991;21:235-40.

11 US Department of Health, Education and Welfare. Smoking and health. In: $A$ Report of the Surgeon General. ing and health. In: A Report of the Surgeon General.

12 Proctor CJ, Smith G. Considerations of the chemical complexity of ETS with regard to inhalation studies. Exp Pathol 1989;37:164-9.

13 Lofroth G. Environmental tobacco smoke: overview of chemical composition and genotoxic components. Muta Res 1989;222:73-80.

14 Kilburn KH. Particles causing lung disease. Environ Health Perspect 1984;55:97-109.

15 Utell MJ. Particulate air pollution and health. New evidence on an old prot

16 Guerin MR, Jenkins RA, Tomkins BA. The chemistry of environmental tobacco smoke: composition and measurement. Chelsea, MI: Lewis Publishers, 1992.

17 Leikauf GD, Leming LM, O'Donnell JR, Doupnik CA. Bronchial responsiveness and inflammation in guinea pigs Bronchial responsiveness and inflammation in guine

18 Sisson JH, Tuma DJ, Rennard SI. Acetaldehyde-mediated cilia dysfunction in bovine bronchial epithelial cells. $A m \mathcal{F}$ Physiol 1991;260:L29-36.

19 Godish T. Formaldehyde exposures from tobacco smoke: a review. Am f Public Health 1989;79:1044-5.

20 Rickard KA, Taylor, Rennard SI. Observations of development to detachment of cultured bovine bronchial epithe- lial cells in response to protease treatment. Am $\mathcal{F}$ Respir Cell Mol Biol 1992;6:414-20.

21 Church DF, Pryor WA. Free-radical chemistry of cigarette smoke and its toxicological implications. Environ Health Perspect 1985;64:111-26.

22 Hogg JC. Bronchial mucosa permeability and its relationship to airways hyperreactivity. Eur $\mathcal{F}$ Respir Dis 1982;122(Suppl): 17-22.

23 Harkema JR, Mariassy A, St. George J, Hyde DM, Plopper CG. Epithelial cells of the conducting airways. A species comparison. In: Farmer SG, Hay DWP, eds. The airway epithelium. Physiology, pathophysiology, and pharmacology. New York: Marcel Dekker, 1991:3-39.

24 von Meyerinck L, Scherer G, Adlkofer F, Wenzel-Hartung $\mathrm{R}$, Brune $\mathrm{H}$, Thomas $\mathrm{C}$. Exposure of rats and hamsters to sidestream smoke from cigarettes in a subchronic inhalation study. Exp Pathol 1989;37:186-9.

25 Takahashi A, Iwasaki I, Ide G. Effects of minute amounts of cigarette smoke with or without nebulized $\mathrm{N}$-nitroso$N$-methyurethane on the respiratory tract of mice. $\mathcal{F p n} \mathfrak{F}$ Cancer Res 1985;76:324-30.

26 Rogers DF, Jeffery PK. Inhibition by oral $N$-acetylcysteine of cigarette smoke-induced "bronchitis" in the rat. Exp Lung Res 1986;10:267-83.

27 Rogers DF, Jeffery PK. Inhibition of cigarette smokeinduced airway secretory cell hyperplasia by indomethacin, dexamethasone, prednisolone, or hydrocortisone in the rat. Exp Lung Res 1986;10:285-98.

28 Jeffrey PK. Anti-inflammatory drugs and experimental bronchitis. Eur f Respir Dis 1986;146(Suppl):245-57.

29 Rogers DF, Jeffery PK. Indomethacin and flurbiprofen speed recovery of rat bronchial epithelium after exposure to cigarette smoke. Exp Lung Res 1986;10:299-312.

30 Rogers DF, Godfrey RWA, Majumdar S, Jeffery PK. Ora $\mathrm{N}$-acetylcysteine speeds reversal of cigarette smokeinduced mucous cell hyperplasia in the rat. Exp Lung Res 1988;14:19-35.

31 Balansky RB, D'Agostini F, Zanacchi P, DeFlora S. Protection by $N$-acetylcysteine of the histopathological and cytogenetical damage produced by exposure of rats to cigarette smoke. Cancer Lett 1992;64:123-31.

32 Wright JL, Hobson JE, Wiggs B, Pare PD, Hogg JC. Airway inflammation and peribronchiolar attachments in the lungs of nonsmokers, current and ex-smokers. Lung 1988;166:277-86.

33 Shields PA, Jeffery PK. The combined effects of vitamin A deficiency and cigarette smoke of rat tracheal epithelium. Br F Exp Pathol 1987;68:705-17.

34 Jeffery PK, Brain AP, Shields PA, Quinn BP, Betts T. Response of laryngeal and tracheo-bronchial surface lining to inhaled cigarette smoke in normal and vitamin A deficient rats: a scanning electron microscopic study. Scanning Microsc 1988;2:545-52.

35 Lasnitizki I, Bollag W. Prevention and reversal by a nonpolar arotinoid (Ro 15-0778) of 3,4-benzpyrene- and cigarette smoke condensate-induced hyperplasia and metaplasia of rodent respiratory epithelia grown in vitro. Eur $\mathcal{f}$ Cancer Clin Oncol 1987;23:861-5.

36 Todisco T, Dottorini M, Rossi R, Baldoncini A, Pulumbo $R$. Normal reference values for regional pulmonary peripheral airspace epithelial permeability. Influence of pneumonectomy and the smoking habit. Respiration 1989;55:84-93.

37 Minty BD, Royston D, Jones JG, Hulands GH. The effect of nicotine on pulmonary epithelial permeability in man. Chest 1984;86:72-4.

38 Coates G, O'Brodovich $\mathrm{H}$. Measurement of pulmonary epithelial permeability with ${ }^{99 m}$ Tc-DTPA aerosol. Semin Nucl Med 1986;16:275-84.

39 Holden WE, Maier JM, Malinow MR. Cigarette smoke extract increases albumin flux across pulmonary endothelium in vitro. $\mathcal{A}$ Appl Physiol 1989;66:443-9.

40 Lundberg JM, Lundblad L, Saria A, Anggard A. Inhibition of cigarette smoke-induced oedema in the nasal mucosa by capsaicin pretreatment and a substance $\mathrm{P}$ antagonist. Naunyn Schiedebergs Arch Pharmacol 1984;326:181-5.

41 Geppetti P, Bertrand C, Baker J, Yamawaki I, Piedmonte $G$, Nadel JA. Ruthenium red, but not capsazepine reduces plasma extravasation by cigarette smoke in rat airways. $\mathrm{Br}$ f Pharmacol 1993;108:646-50.

42 Burns AR, Hosford SP, Dunn LA, Walker DC, Hogg JC. Respiratory epithelial permeability after cigarette smoke
exposure in guinea pigs. $7 \mathrm{Appl}$ Physiol 1989;66:2109-16.

43 Witten ML, Lemen RJ, Quan SF, Sobonya RE, Roseberry $\mathrm{H}$, Stevenson JL, et al. Acute cigarette smoke exposure increases alveolar permeability in rabbits. Am Rev Respir Dis 1985;132:321-5.

44 Mordelet-Damrine $M$, Leguern-Stanislas G, Chinet TC Barritault L, Chretien J, Huchon GJ. Effects of tobacco smoke on respiratory epithelial clearance of DTPA and on lung histology in rats. Eur Respir $\mathcal{f} 1991 ; 4: 839-44$.

45 Boucher RC, Johson J, Inoue S, Hulbert W, Hogg JC. The effect of cigarette smoke on permeability of guinea pig airways. Lab Invest 1980;43:94-100

46 Hulbert WC, Forster BB, Mehta JG, Man SF, Molday RS, Walker BA, et al. Study of airway epithelial permeability with dextran. $\mathcal{F}$ Electron Microsc Tech 1989;11:137-42.

47 Hulbert WC, Walker DC, Jackson A, Hogg JC. Airway permeability to horseradish peroxidase in guinea pigs: the permeability to horseradish peroxidase in guinea pigs: the repair phase after injury
Respir Dis 1981;123:320-6.

48 Rutten AA, Jongen WM, de Haan LH, Hendriksen EG, Koeman JH. Effect of retinol and cigarette-smoke condensate on dye-coupled intercellular communication between hamster epithelial cells. Carcinogenesis 1988;9:315-20. 
49 van der Zandt PT, de Feijter AW, Homan EC, Spaaij C, de Haan LH, van Aelst AC, et al. Effects of cigarette smoke condensate and 12-O-tetradecanoylphorbol-13-acetate on gap junction structure and function in cultured cells. Carcinogenesis 1990;11:883-8.

$50 \mathrm{McKarns}$ SC, Doolittle DJ. A quantitative approach to assessing intercellular communication: studies on cigarette smoke condensates. Toxicol Appl Pharmacol 1991;111:58 68 .

51 Rose MC. Mucins: structure, function, and role in pulmonary diseases. Am $\mathcal{F}$ Physiol 1992;263:L413-L429.

52 Wanner A. A review of the effects of cigarette smoke on airway mucosal function. Eur $\mathcal{f}$ Respir Dis 1985;66(Suppl):49-53.

53 Lippman $M$, Schlesinger RB. Interspecies comparisons of particle deposition and mucociliary clearance. $\mathcal{f}$ Toxicol Environ Health 1984;13:441-69.

54 Richardson MA. Upper airway complications of cigarette smoking. F Allergy Clin Immunol 1988;91:1032-5.

55 Stanley PJ, Wilson R, Greenstone MA, MacWilliam L, Cole PJ. Effect of cigarette smoking on nasal mucociliary clearance and ciliary beat frequency. Thorax 1986;41:51923.

56 Lindberg S, Dolata J. NK1 receptors mediate the increase in mucociliary activity produced by tachykinins. Eur $\mathcal{F}$ Pharmacol 1993;231:375-80.

57 Rubin BK, Ramirez O, Zayas JG, Finegan B, King M Respiratory mucus from asymptomatic smokers is better hydrated and more easily cleared by mucociliary action. Am Rev Respir Dis 1992;145:545-7.

58 Sperber K, Gollub E, Goswani S, Kalb TH, Mayer L Marom Z. In vivo detection of a novel macrophagederived protein involved in the regulation of mucus-like glycoprotein secretion. Am Rev Respir Dis 1992;146:1589 97.

59 Knowles MR, Buntin WH, Bromberg, Gatzy JT, Boucher RC. Measurements of transepithelial electric potential differences in the trachea and bronchi of human subjects in vivo. Am Rev Respir Dis 1982;126:108-12.

60 Agnew JE, Pavia D, Clarke SW. Mucus clearance from peripheral and central airways of asymptomatic cigarette

61 Agnew JE, Lopez-Vidriero MT, Parvia D, Clarke SW. Functional small airways defence in symptomless cigarette smokers. Thorax 1986;41:524-30

62 Welsh MJ. Cigarette smoke inhibition of ion transport in canine tracheal epithelium. $\mathcal{F}$ Clin Invest 1983;71:1614-23.

63 Desanctis GT, Kelly SM, Saettea MP, Shiner RJ, Stril JL Hakim TS, et al. Hyporesponsiveness to aerosolized but not infused methacholine in cigarette-smoking dogs. $A m$ Rev Respir Dis 1987;135:338-44.

64 Richardson PS, Peatfield AC. The control of airway mucus secretion. Eur $\mathcal{F}$ Respir Dis 1987;153(Suppl):43-51.

65 Kou HP, Rodhe JA, Barnes PJ, Rogers DF. Cigarette smoke-induced airway goblet cell secretion: dose-dependent differential nerve secretion. $A m \quad \mathcal{J}$ Physio 1992;263:L161-7.

66 Rogers DF, Turner NC, Marriott C, Jeffery PK. Cigarette smoke-induced "chronic bronchitis": a study in situ of laryngo-tracheal hypersecretion in the rat. Clin $\mathrm{Sci}$ 1987;72:629-37.

67 Peatfield AC, Davies JR, Richardson PS. The effect of tobacco smoke upon airway secretion in the cat. Clin Sci 1986;71:179-87.

68 Hummer B, Purnama I, Hahn HL. Stimulation of submucosal glands by nicotine applied locally to the airway mucosa. Klin Wochenschr 1988;66(Suppl):161-9.

69 Hobson J, Wright J, Churg A. Histochemical evidence of generation of active oxygen species on the apical surface of cigarette-smoke-exposed tracheal explants. Am $\mathcal{f}$ Pathol 1991;139:573-80.

70 Sisson JH, Leise LK, Smith RA, Rennard SI, Cohen SM Acrolein induces bronchial epithelial cell ciliostasis that can be blocked by N-acetylcysteine. Am Rev Respir Dis 1991;143:A490.

71 Sisson JH, Tuma DJ, Rennard SI. Acetaldehyde-mediated cilia dysfunction in bovine bronchial epithelial cells. $A m \mathcal{F}$ Physiol 1991;260:L29-L36.

72 Maggi CA. Tachykinin receptors in the airways and lung: what should we block? Pharmacol Res 1990;22:527-32.

73 Morimoto H, Yamashita M, Matsuda A, Miyake H, Fujii T. Effects of FR 113680 and FK 224, novel tachykinin receptor antagonists on cigarette smoke-induced rat tra-
cheal plasma extravasation. Eur $\mathcal{f}$ Pharmacol 1992;224: cheal

74 Lundberg JM, Martling CR, Saria A, Folkers K, Rosell S. Cigarette smoke-induced airway oedema due to activation of capsaicin-sensitive vagal afferents and substance $P$ release. Neuroscience 1983;10:1361-8.

75 Dusser DJ, Djokic TD, Borson DB, Nadel JA. Cigarette smoke induces bronchoconstrictor hyperresponsiveness to substance $P$ and inactivates airway neutral endopeptidase in the guinea pig. Possible role of free radicals. $\mathcal{f}$ Clin Invest 1989;84:900-6.

76 Von Essen SG, Rennard SI, O’Neill D, Ertl RF, Robbins RA, Kayama $S$, et al. Bronchial epithelial cells release neutrophil chemotactic activity in response to tachykinins. Am $\mathcal{F}$ Physiol 1992;263:L226-L231.

77 DeRose V, Robbins RA, Spurzen JR, Snider RM, Thiele G, Rennard SI, et al. Substance P increased neutrophil adhesion to bronchial epithelial cells. Am Rev Respir Dis 1992;145: A681.

78 Aguayo SM, Kane MA, King TE Jr, Schwarz MI, Grauer L, Miller YE. Increased levels of bombesin-like peptides in the lower respiratory tract of asymptomatic cigarette smokers. $\mathcal{f}$ Clin Invest 1989;84:1105-13.

79 Meloni F, Bertoletti R, Corsico A, DiFazio P, Cecchettin M, Gialdroni-Grassi G. Bombesin/gastrin releasing peptide levels of peripheral mononuclear cells, monocytes, and alveolar macrophages in chronic bronchitis. Int $\mathcal{f}$ Tissue React 1992;14:195-201.

80 Shipp MA, Tarr GE, Chen CY, Surtzer SN, Hersh LH, Stein $\mathrm{H}$, et al. $\mathrm{CD} 10 /$ neutral endopeptidase 24.11 hydrolyzes bombesin-like peptides and regulates the growth of small cell carcinomas of the lung. Proc Natl Acad Sci USA 1991;88:100662-6.

81 Munakata M, Masaki Y, Sakuma I, Ukita H, Otsuka Y, Homma Y, et al. Pharmacologic differentiation of epithelium-derived relaxing factor from nitric oxide. $\mathcal{F} A p p l$ Physiol 1990;69:665-70.

82 Robbins RA, Hamel FG, Floreani AA, Gossman GI Nelson KJ, Belenky S, et al. Bovine bronchial epithelia cells metabolize $\mathrm{L}$-arginine to $\mathrm{L}$-citrulline: possible role of nitric oxide synthase. Life Sci 1993;52:709-16.

83 Jain B, Rubinstein I, Robbins RA, Leise KL, Sisson JH Nitric oxide modulates ciliary activity in airway epithelium. Am Rev Respir Dis 1993;147:A937.

84 Jansen A, Drazen JM, Loscalzo J, Brown R, Sugarbaker DA, Stamler JS. S-nitrosothiols: a new class of bronchodilators. Am Rev Respir Dis 1991;143:A630.

85 Endo T, Uchida Y, Matsumoto H, Suzuki N, Nomura A Hirata F, et al. Regulation of endothelin-1 synthesis in cultured guinea pig airway epithelial cells by various cytokines. Biochem Biophys Res Commun 1992;186 1594-9.

86 Sparrows D, Glynn RJ, Cohen M, Weiss ST. The relationship of the peripheral leukocyte count and cigarette smoking to pulmonary function among adult men. Chest 1984;86:383-6.

87 Hunninghake GW, Crystal RG. Cigarette smoking and lung destruction: accumulation of neutrophils in the lungs of cigarette smokers. Am Rev Respir Dis 1983;128:833-8.

88 Reynolds HV. Bronchoalveolar lavage. Am Rev Respir Dis 1987;135:250-63.

89 Robbins RA, Shoji S, Linder J, Gossman GL. Bronchial epithelial cells release chemotactic activity for lymphocytes. Am f Physiol 1989;257:L109-15.

90 Anderson R, Theron AJ, Richards GA, Myer MS, van Rensburg AJ. Passive smoking by humans sensitizes circulating neutrophils. Am Rev Respir Dis 1991:144:570-4.

91 Totti N, McCusker KT, Campbell EJ, Griffin GL, Senio RM. Nicotine is chemotactic for neutrophils and enhances neutrophil responsiveness to chemotactic peptides. $S \mathrm{ci}$ ence 1984;223:169-71

92 Nowak D, Ruta U, Paisecka G. Nicotine increases human polymorphonuclear leukocytes chemotactic response - a possible additional mechanism of lung injury in cigarett smokers. Exp Pathol 1990;39:37-43.

$93 \mathrm{Kew}$ RR, Ghebrehiwet B, Janoff A. The role of complement in cigarette smoke-induced chemotactic activity of lung fluids. Am Rev Respir Dis 1986;133:478-81.

94 Robbins RA, Gossman GL, Nelson KJ, Koyama S Thompson AB, Rennard SI. Inactivation of chemotactic factor inactivator by cigarette smoke. A potential mechanism of modulating neutrophil recruitment to the lung. $A m$ Rev Respir Dis 1990;142:763-8.

95 Gadek JE, Pacht ER. The protease-antiprotease imbalance within the lung: implications for the pathogenesis of emphysema. Lung 1990;168:552-64

96 Eling TE, Danilowicz RM, Henke DC, Sivarajah K, Yankaskas JR, Boucher RC. Arachidonic acid metabolism by canine tracheal epithelial cells. Product formation and relationship to chloride secretion. $f$ Biol Chem 1986;261:12841-9.

97 Churchill L, Chilton FH, Resau JH, Bascom R, Hubbard WC, Proud D. Cyclooxygenase metabolism of endogenous arachidonic acid by cultured human tracheal epithelial cells. Am Rev Respir Dis 1989;140:449-59.

98 Wennmalm A, Benthin G, Granstrom EF, Persson L Petersson AS, Winell S. Relation between tobacco use and urinary excretion of thromboxane $A_{2}$ and prostacyclin metabolites in young men. Circulation 1991:83:1698-704.

99 Wu Wang CY, Wang SL, Lim C, Milles M, Slomiany A Slomiany BL. Cigarette smoking reduces human salivary eicosanoids. Prostaglandins Leukot Essent Fatty Acids 1992;47:101-4.

100 Nagase T, Fukuchi Y, Shimizu T, Yamaoka M, Matsuse T, Hirose $\mathrm{T}$, et al. The influence of cigarette smoke on metabolism of icosanoids in rat lung in terms of variation of 15-hydroxeicosatetraenoic acid and 11-dehydrothromboxane $\mathrm{B}_{2}$. Nippon Kyobu Shikkan Gakkai Zasshi 1989;27:1193-7.

101 Leikauf GD, Leming LM, O'Donnell JR, Doupnik CA. Bronchial responsiveness and inflammation in guinea pigs exposed to acrolein. F Appl Physiol 1989;66:171-8.

102 Jeremy JY, Mikhailidis DP, Dandona P. Muscarinic stimulation of prostanoid synthesis by isolated rat trachea: calcium dependency and effect of cortisol and cigarette calcium dependency and effect of cortisol

103 Thomas PS, Schreck RE, Lazarus SC Tobacco smoke releases preformed mediators from canine mast cells and modulates prostaglandin production. Am $\mathcal{f}$ Physiol 1992;263:L67-72

104 Cox G, Gauldie J, Jordana M. Bronchial epithelial cellderived cytokines (G-CSF and GM-CSF) promote the survival of peripheral blood neutrophils in vitro. $A m \mathcal{f}$ Respir Cell Mol Biol 1992;7:507-13.

105 Becker S, Koren HS, Henke DC. Interleukin-8 expression 
in normal nasal epithelium and its modulation by infection with respiratory syncytial virus and cytokines tumor necrosis factor, interleukin-1, and interleukin-6. Am $\mathcal{f}$ Respir Cell Mol Biol 1993;8:20-7.

106 Ohtoshi T, Vancheri C, Cox G, Gauldie J, Dolovich J, Denburg JA, et al. Monocyte-macrophage differentiation
induced by human upper airway epithelial cells. $A m \mathcal{F}$ induced by human upper airway epir Cell Mol Biol 1991;4:255-63.

107 Francus T, Romano PM, Manzo G, Fonacier L, Arango N, Szabo P. IL-1, IL-6, and PDGF mRNA expression in alveolar cells following stimulation with a tobacco-derived antigen. Cell Immunol 1992;145:156-74.

108 Dubar V, Gosset P, Aerts C, Voisin C, Wallaert B, Tonnel AB. In vitro acute effects of tobacco smoke on tumor necrosis factor alpha and interleukin- 6 production by alveolar macrophages. Exp Lung Res 1993;19:345-59.

109 Soliman DM, Twigg HL III. Cigarette smoking decreases bioactive interleukin- 6 secretion by alveolar macrophages. Am $\mathcal{F}$ Physiol 1992;263:L471-8.

110 Hance AJ, Basset G, Saumon G, Danel C, Valeyre D, Battesti JP, et al. Smoking and interstitial lung disease: the effect of cigarette smoking on the incidence of pulmonary histiocytosis X and sarcoidosis. Ann NY Acad $S_{c i}$ 1986;465:643-56.

111 Tosi MF, Stark JM, Smith CW, Hamedani A, Gruenert DC, Infeld MD. Induction of ICAM-1 expression on human airway epithelial cells by inflammatory cytokines: human airway epithelial cells by inflammatory cytokines: effects on neutrophil-epithelial

112 MacNee W, Wiggs B, Belzberg AS, Hogg JC. The effect of cigarette smoking on neutrophil kinetics in human lungs. N Engl f Med 1989;321:924-8.

113 Bosken CH, Doerschuk CM, English D, Hogg JC. Neutrophil kinetics during active cigarette smoking in rabbits. $\mathcal{f}$ Appl Physiol 1991;71:630-7.

114 Lehr HA, Kress E, Menger MD. Involvement of 5-lipoxygenase products in cigarette smoke-induced leukocyte/ endothelium interaction in hamsters. Int $\mathcal{F}$ Microcirc Clin endothelium interaction

115 Drost EM, Selby C, Lannan S, Lowe GDO, MacNee W. Changes in neutrophil deformability following in vitro smoke exposure: mechanism and protection. Am $\mathcal{J}$ Respir Cell Mol Biol 1992;6:287-95.

116 Klut ME, Doerschuk CM, Van Eeden SF, Burns AR, Hogg JC. Activation of neutrophils within pulmonary microvessels of rabbits exposed to cigarette smoke. Am $\mathcal{F}$ Respir Cell Mol Biol 1993;9:82-9.

117 Baluk P, Hatzidakis A, Nadel JA, McDonald DM Chronic exposure to cigarette smoke potentiates capsaicin-induced neutrophil adhesion in rat trachea. Am Rev Respir Dis 1992;145:A188.

118 Robbins RA, Koyama S, Spurzem JR, Rickard KA, Nelson $\mathrm{KJ}$, Gossman GL, et al. Modulation of neutrophil and mononuclear cell adherence to bronchial epithelial cells. Am ₹ Respir Cell Mol Biol 1992;7:19-29.

119 Selby C, Drost E, Brown D, Howie S, MacNee W. Inhibition of neutrophil adherence and movement by acute cigarette smoke exposure. Exp Lung Res 1992;18:813-27.
120 Holt PG. Immune and inflammatory function in cigarette smokers. Thorax 1987;42:241-9.

121 Savage SM, Donaldson LA, Cherian S, Chilukuri R, White VA, Sopori ML. Effects of cigarette smoke on the immune response. II. Chronic exposure to cigarette smoke inhibits response. II. Chronic exposure to cigarette smoke inhibits surface immunoglobulin-mediated respo

122 Spurzem JR, Sacco O, Rossi GA, Beckmann JD, Rennard SI. Regulation of major histocompatibility complex class II gene expression on bovine bronchial epithelial cells. $\mathcal{f}$ Lab Clin Med 1992;120:94-102.

123 McDevitt CA, Beck GJ, Ciunga MJ, O'Brien J. Cigarette smoke degrades hyaluronic acid. Lung 1989;167:237-45.

124 Pladsen P, Beckman J, Rennard S, Romberger D. Cigarette smoke extract modulates bronchial epithelial cell fibronectin release. Am Rev Respir Dis 1992;145:A826.

125 Cantral DE, Veys T, Sission JH, Rennard SI, Spurzem JR. Exposure of bronchial epithelial cells to cigarette smoke extract impairs migration. Am Rev Respir Dis 1993;147:A46.

126 Barrett JC, Lamb PW, Wiseman RW. Multiple mechanisms for the carcinogenic effects of asbestos and other mineral fibers. Environ Health Perspect 1989;81:81-9.

127 Kamp DW, Graceffa P, Pryor WA, Weitzman SA. The role of free radicals in asbestos-induced disease. Free Radic Biol Med 1992;12:293-315.

128 McFadden D, Wright J, Wiggs B, Churg A. Cigarette smoke increases the penetration of asbestos fibers into smoke increases the penetration of asbes
airway walls. $A m \mathcal{F}$ Pathol 1986;123:95-9.

129 Churg A, Wright JL, Hobson J, Stevens B. Effects of cigarette smoke on the clearance of short asbestos fibres from the lung and a comparison with the clearance of long asbestos fibres. Int $\mathcal{F}$ Exp Pathol 1992;73:287-97.

130 Churg A, Hobson J, Wright J. Effects of cigarette smoke dose and time after smoke exposure on uptake of asbestos fibers by rat tracheal epithelial cells. Am $\mathcal{f}$ Respir Cell Mol Biol 1990;3:265-9.

131 Churg A, Hobson J, Berean K, Wright J. Scavengers of active oxygen species prevent cigarette smoke-induced asbestos fiber penetration in rat tracheal explants. $A m \mathcal{F}$ Pathol 1989;135:599-603.

132 Keeling B, Hobson J, Churg A. Effects of cigarette smoke on epithelial uptake of non-asbestos mineral particles in tracheal organ culture. Am $₹$ Respir Cell $\mathrm{Mol}$ Biol 1993;9:335-40.

133 Takahashi K. Patho-physiological changes in the lung parenchyma caused by exposure of tobacco smoke in the hamster. Nippon Kyobu Shikkan Gakkai Zasshi (fapanese hamster. Nippon Kyobuc Dis) 1991;29:190-6.

134 Nilsson K, Henriksson R, Cai Yo Hellstroms S, Hornqvist-Bylunds $S$, Bjermer $L$. Effects of tobacco smoke on radiation-induced pneumonitis in rats. Int $\mathcal{f}$ Radiat Biol 1992;62:719-27.

135 Nishikawa $M$, Ikeda $H$, Nishiyama $H$, Yamakawa $H$ Suzuki S, Okubo T. Combined effects of ozone and cigarette smoke on airway responsiveness and vascular permeability in guinea pigs. Lung 1992;170:311-22. 